NOTE

\title{
Effects of a shark repulsion device on rocky reef fishes: no shocking outcomes
}

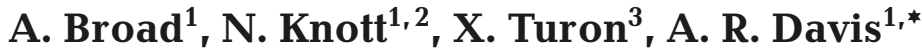 \\ ${ }^{1}$ Institute for Conservation Biology \& School of Biological Sciences, University of Wollongong, Wollongong, \\ New South Wales 2522, Australia \\ ${ }^{2}$ Jervis Bay Marine Park, PO Box 89, Huskisson, New South Wales 2540, Australia \\ ${ }^{3}$ Centre for Advanced Studies, 17300 Blanes, Girona, Spain
}

\begin{abstract}
Shark repulsion devices (SRDs; e.g. Shark Shield ${ }^{\mathrm{TM}}$ ) use an electric field to deter large and potentially dangerous sharks. The use of these devices is becoming increasingly widespread for a range of recreational activities as well as scientific and commercial diving. We sought to determine if SRDs might modify the behaviour of chondrichthyan and osteichthyan fishes and thereby impact on fish assemblages, as well as potentially bias diver census techniques. To assess the potential impacts of this technology, we attached SRDs to baited remote underwater video (BRUV) units and deployed them on shallow rocky reefs in Jervis Bay Marine Park (New South Wales, Australia). We did not detect any impacts of the SRD on the diversity or relative abundance of shallow-reef fishes. In addition, approach of fishes to the bait did not differ whether the SRDs were on or off. At the smallest spatial scale we investigated, contact with the bait was half as frequent when the SRD was switched on compared to when it was off. Surprisingly, even the cartilaginous species were apparently unaffected by the SRD, with the eastern fiddler ray Trygonorrhina fasciata making contact with the bait several times when SRDs were activated. We contend that the ecological impacts of SRDs at all but the smallest scales are minimal and they are unlikely to introduce bias in assessments of fish assemblages, at least for non-cartilaginous and small cartilaginous species.
\end{abstract}

KEY WORDS: Ampullae of Lorenzini $\cdot$ Baited remote underwater video $\cdot$ Elasmobranch $\cdot$ Electrical pulse · Jervis Bay Marine Park · Sampling bias · Shark-shield · Underwater visual census

Resale or republication not permitted without written consent of the publisher

\section{INTRODUCTION}

The detection of weak electrical fields is heightened in many fishes, especially the chondrichthyans (von der Emde 1998). Among the sharks and rays, the ampullae of Lorenzini are often concentrated around the head and enable the detection of low-frequency (i.e. $0.5 \mathrm{~Hz}$ ) electric fields as weak as $1 \mathrm{nV} \mathrm{cm}^{-2}$ (Murray 1962, Kalmijn 1971, von der Emde 1998). In addition, some osteichthyes (e.g. Siluriformes) possess ampullary organs and are capable of some degree of electroreception (von der Emde 1998). The extreme sensitivity of chondrichthyans to electric fields has been targeted to reduce the threat posed to humans by large, potentially dangerous sharks. Shark repulsion devices (SRDs) that produce electrical pulses are now commercially available, and it is claimed that they can create an electrical field around a diver (or surfboard, kayak, etc.) that is detected by the ampullae of Lorenzini, creating muscle spasms and driving sharks from the vicinity (www.sharkshield.com).

Our concerns about the effects of these devices were 2 -fold. We were interested in (1) the general ecological effects of their usage and (2) the potential scientific bias that they may introduce in the census of fish assemblages. The ecological effects of their usage in 
marine protected areas, such as Jervis Bay Marine Park in southern New South Wales (NSW), Australia, were of particular concern. Marine parks are often required to balance the conservation of biological diversity as well as manage a range of human activities within their boundaries (www.mpa.nsw.gov.au). Significant recreational SCUBA diving is often concentrated in these locations; in the case of Jervis Bay Marine Park, more than 20000 dives occur each year (NSW Marine Park Authority unpubl. data) and the use of SRDs will likely increase. Marine parks are also popular locations for a range of other activities (e.g. snorkelling, spearfishing, swimming, surfing, kayaking) that in future are likely to involve the use of these devices. Hence, it is important for management authorities to assess the potential impacts of SRDs. From a scientific perspective, the potential for these devices to introduce bias in fish censuses may be particularly important for long-running sampling programmes that may be comparing data collected with and without SRDs where their use may confound an assessment of temporal change.

Our concerns about the effects of electrical repulsion devices were heightened by field observations of several fishes behaving strangely near these devices (authors' pers. obs.). We reasoned that they may not only affect large sharks (the target of these devices) but also common chondrichthyans and possibly osteichthyans. There appear to be no published studies assessing the effects of SRDs on fishes generally or over what distances SRDs may repel chondrichthyans. Hence, we tested 2 null hypotheses: (1) the diversity and abundance of fishes observed would not differ in the presence of activated or inactive SRDs over scales of metres and tens of metres, and (2) that the behaviour of fishes would not be affected over smaller spatial scales. In order to assess the potential impacts of this technology, we elected to test these hypotheses by attaching SRDs to baited remote underwater video (BRUV) units.

\section{MATERIALS AND METHODS}

Study location and SRDs. This assessment of the potential ecological effects of the use of SRDs was done in Jervis Bay Marine Park. Large areas of rocky reef occur in the park similar to many sections of the temperate east coast of Australia. We sampled subtidal reefs along the northwestern edge of the bay, extending from Green Point $\left(35.0095^{\circ} \mathrm{S}, 150.4583^{\circ} \mathrm{E}\right)$ to Dart Point $\left(35.0440^{\circ} \mathrm{S}, 150.4638^{\circ} \mathrm{E}\right.$ ) in April (austral autumn) 2009. Two identical BRUV units (see Cappo et al. 2004, Malcolm et al. 2007) were deployed onto shallow rocky reefs ( 4 to $7 \mathrm{~m}$ ).
The SRD Shark Shield ${ }^{\mathrm{TM}}$ (Freedom 7 ) is a small, battery-operated instrument $(15 \times 12 \times 4 \mathrm{~cm})$ that contains 2 electrodes and that when operating and immersed in water produces an elliptical electric field via an antenna. The antenna measures $2.2 \mathrm{~m}$ in length and the 3-dimensional electrical field it creates is approximately $4 \mathrm{~m}$ either side of this antenna (www.sharkshield.com).

BRUV system and analysis of video footage. BRUV is a widely used technique to assess fish assemblages (e.g. Cappo et al. 2004, Malcolm et al. 2007). Our system consisted of a video camera (Sony or Canon highresolution Mini-DV) in a plastic waterproof housing enclosed within a galvanised steel frame. Bait was contained within a plastic mesh container attached to a $1 \mathrm{~m}$ arm extending from the camera housing. The SRD main unit was attach to the camera housing with Velcro straps and the antenna was secured to the plastic bait arm with cable ties. This arrangement meant that the bait was well enclosed within the electrical field. Crushed pilchards Sardinops sagax (400 g) was placed into the bait container and the bait was renewed for each deployment. Video was recorded for $30 \mathrm{~min}$ at each deployment. Each BRUV was allowed $5 \mathrm{~min}$ to settle on the reef before video sampling commenced. Previous studies have indicated that a 30 min deployment provides adequate estimates of the diversity of fishes on an area of reef (Willis \& Babcock 2000, Wraith 2007).

To test the stated hypotheses, half of the BRUV deployments were with operating SRDs and for the remainder they were not operating $(n=10)$; this was determined by random draw. Each BRUV deployment was separated by a minimum of $150 \mathrm{~m}$. A single experienced observer (A.B.) examined the video recordings. Each fish species observed in each deployment was recorded, providing an estimate of species richness $(S)$. Relative abundance was determined by recording the maximum number of fish of each species viewed at any one time during the deployment (Max $n)$. To evaluate small-scale effects of the SRD, we quantified approach to and contact with the bait container by fishes. Approach was measured by delineating a hemispherical area $20 \mathrm{~cm}$ wide and $20 \mathrm{~cm}$ high centred on the bait container and counting any individuals entering this area during 8 random $5 \mathrm{~s}$ periods within each deployment. We also quantified contact with the bait container (number of pecks) during the 30 min of deployment and the species responsible.

Statistical analysis. We used univariate and multivariate analyses to test our hypotheses. We used $t$-tests to compare means for $S$, Total Max $n$, Max $n$ for targeted fish species, as well as approach and pecking rates when SRDs were activated or inactive (Systat v. 12). Assumptions of normality and homogeneity of variances were assessed visually prior to proceeding with each analysis. 
Data from none of the variables required transformation. Multivariate patterns in the fish assemblages were displayed with non-metric multidimensional scaling (NMDS) and analysed using analysis of similarities (ANOSIM) (PRIMER v. 6). Bray-Curtis measures of dissimilarity were calculated for Max $n$ and presence/absence data in order to test for differences in relative abundance and composition (and frequency of occurrence) for the multivariate data set.

\section{RESULTS}

A diverse and representative range of shallow rocky reef fishes were observed in our recordings in Jervis Bay, consisting of 6 chondrichthyan and 51 osteichthyan species. The operation of the SRD did not affect the assemblages of rocky reef fishes, irrespective of whether abundance or presence/absence data were analysed (global $\mathrm{R}=$ 0.002 and $0.001 ; \mathrm{p}=0.418$ and 0.421 respectively; permutations $=999 ;$ Fig. 1 ). $S$ and Max $n$ of fishes were similar with or without the SRD operating (Fig. 2a,b). Max $n$ of the osteichthyans and the chondrichthyans did not differ and none of the individual species of fish showed a response. All species had very similar maximum numbers within the field of view around the bait independent of the operation of the SRD. Southern Maori wrasse Ophthalmolepis lineolatus and

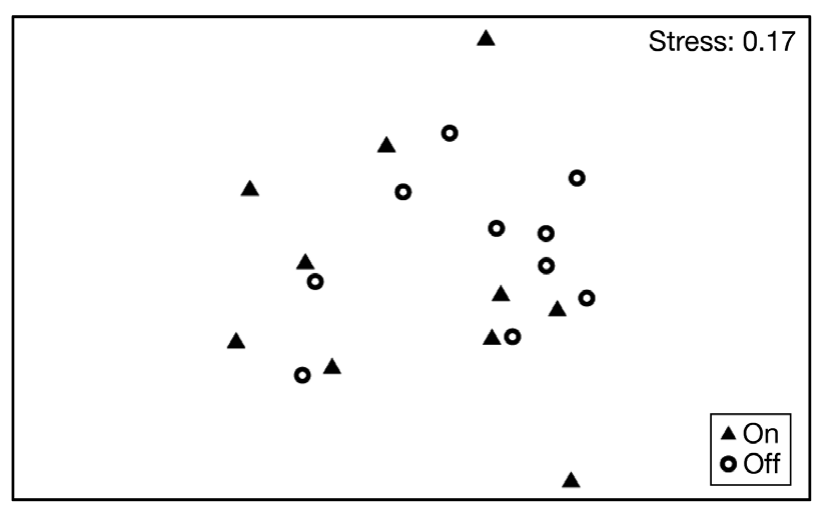

Fig. 1. Temperate reef fish assemblages in the presence of active and inactive shark repulsion devices (SRDs). Assemblages were sampled using baited video in Jervis Bay Marine Park. Untransformed Bray-Curtis distances are presented in the non-metric multidimensional scaling (NMDS)
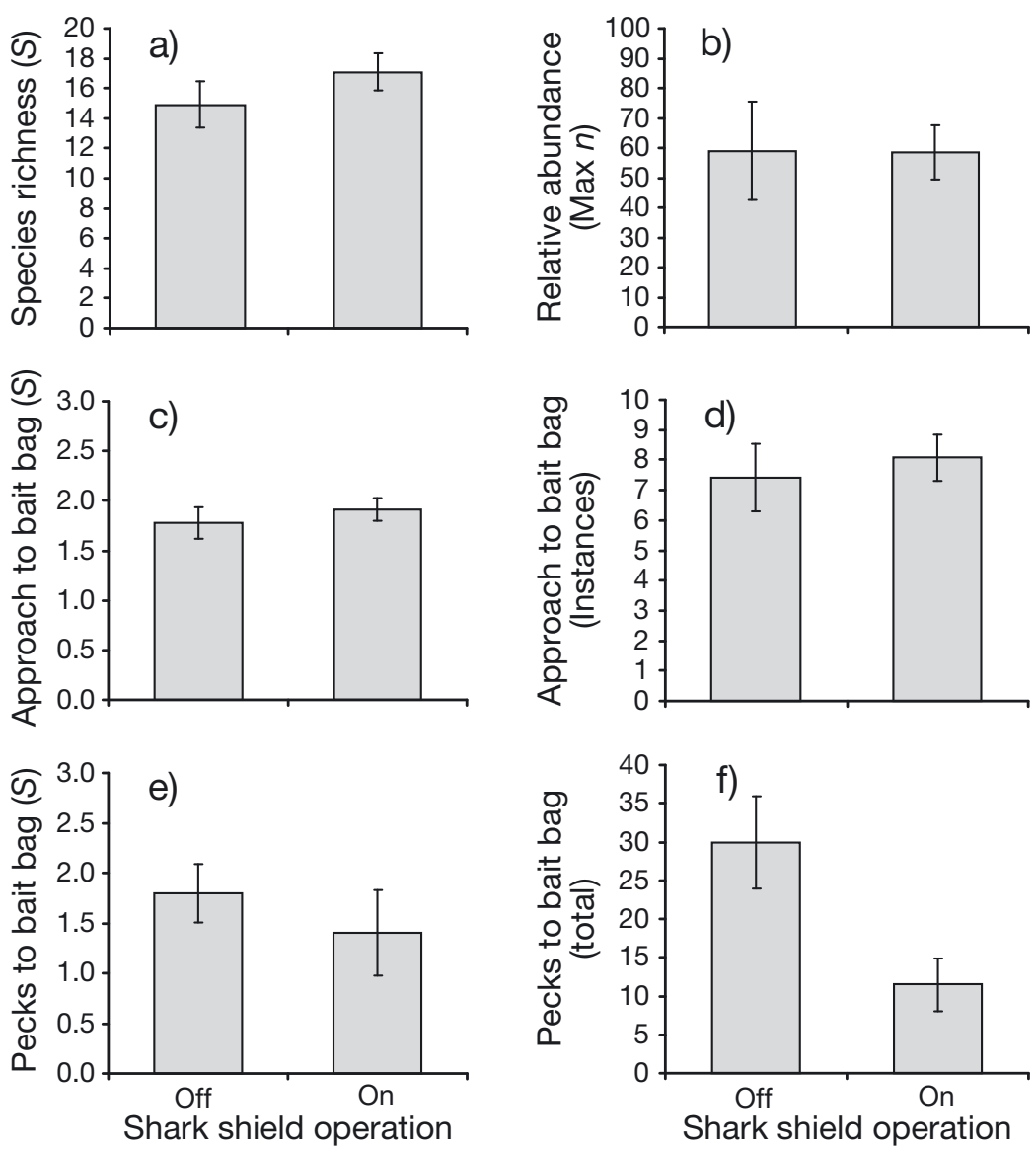

Fig. 2. Temperate reef fish diversity and relative abundance in the presence of active and inactive shark repulsion devices (SRDs; 'Shark Shield'). Bars represent mean $\pm \mathrm{SE}(\mathrm{n}=10)$. (a) Species richness $(S)$, (b) relative abundance (Max $n)$, (c) $S$ of fishes approaching the bait container, (d) number of instances fishes approached the bait container, (e) $S$ of those contacting the bait container (pecks) and (f) total number of pecks. See 'Materials and methods' ('BRUV system and analysis of video footage') for definition of 'approach'

crimson-banded wrasse Notolabrus gymnogenis were the most abundant species at the bait and were representative of the other fish species in that they were unaffected by the operation of the SRD.

We did not detect differences in the approach of fishes to the bait (within tens of centimetres); the number and diversity of fishes were very similar irrespective of the operation of the SRD (Fig. 2c,d). This indicated that even over relatively small scales the fishes were unaffected by the SRD. The number of pecks to the bait container, however, tended to occur more often when the SRD was not operating, with almost twice as many pecks when the SRDs were off $(t=$ 2.657, $\mathrm{p}=0.016, \mathrm{df}=18$; Fig. 2e,f). A total of 8 species $(14 \%)$ pecked at the bait container during the course of the experiment, and 5 of these species pecked when the SRDs were activated. This included 1 elasmobranch, the eastern fiddler ray Trygonorrhina fasciata. 


\section{DISCUSSION}

The increasing usage of SRDs for a wide range of recreational activities and scientific and commercial diving necessitated an assessment of their potential ecological effects on non-target species. In the present study, we did not detect any substantial effects of an electrical SRD on shallow-reef fish assemblages, including several chondrichthyans. We assessed the effects of SRDs on diversity and abundance of fishes over the scales of tens of metres, metres and down to tens of centimetres. Fish were not repelled by the operation of this electrical device over these spatial scales, unless repulsion occurred at distances beyond which the camera could record.

The SRD only affected the behaviour of the fish in very close proximity to the bait. At such close range even humans are affected by the electrical pulses emitted from the transmitter unit and the antenna. This effect at close range may explain our initial observation of strange behaviour of fishes in close proximity to the SRD, involving involuntary muscle spasm. However, shallow rocky fishes did not appear to be repelled over larger distances, as the abundances and species richness of fishes did not differ whether the SRD was operating or not. The lack of the large-scale effect (metres to tens of metres) supports statements made by the producers of the SRD that the signal will not affect osteichthyans. We contend, therefore, that SRDs are unlikely to disturb fishes, at least on shallow rocky reefs in SE Australia, nor would we expect them to bias outcomes of underwater visual census.

As SRDs interfere with electro-reception in chondrichthyans we anticipated that these animals would be particularly sensitive to the devices. Surprisingly, this did not appear to be the case as fiddler rays Trygonorrhina fasciata, eagle rays Myliobatis australis, a yellowback stingaree Urolophus sufflavus and a spotted catshark Asymbolus rubiginosus all approached the bait while the SRD was active; the fiddler rays pecked the bait while the SRD was operating. With just 6 elasmobranch species encountered on our tapes it may be premature to assert that small cartilaginous species are unaffected and any effects on large and potentially dangerous species remains untested.

Although the present study provides no evidence that these kinds of SRD dramatically affect demersal elas-

Editorial responsibility: Hans Heinrich Janssen, Oldendorf/Luhe, Germany mobranchs, more research will be required to better understand the impacts of the use of these devices. The endangered grey nurse shark Carcharias taurus poses an excellent example of the issues that need to be considered with the widening use of SRDs. Current legislation in NSW prohibits the use of SRDs in the critical habitat of this species (www.dpi.nsw.gov.au/fisheries/ species-protection/conservation/what/register/ grey-nurse-shark\#DivingRegulations).

Taken together our data indicate that the wearing of SRDs by those engaging in recreational or scientific activities is unlikely to have negative impacts on fish assemblages or bias censuses of fish assemblages, at least for shallow rocky reef assemblages in SE Australia. However, we recommend that researchers using or planning to use SRDs incorporate an assessment of their SRD units into their work, as effects may vary at locations with different fish assemblages.

Acknowledgements. This work was supported by the New South Wales Marine Parks Authority and the Institute for Conservation Biology, University of Wollongong. We thank M. Fackerell for his assistance in the field. Comments by $\mathrm{M}$. Fackerell, A. Martin and 3 anonymous reviewers improved earlier drafts. This represents contribution no. 294 from the Ecology and Genetics Group, University of Wollongong.

\section{LITERATURE CITED}

Cappo M, Speare P, De'ath G (2004) Comparison of baited remote underwater video stations (BRUVS) and prawn (shrimp) trawls for assessments of fish biodiversity in interreefal areas of the Great Barrier Reef Marine Park. J Exp Mar Biol Ecol 302:123-152

Kalmijn AJ (1971) The electric sense of sharks and rays. J Exp Biol 55:371-383

Malcolm HA, Gladstone W, Lindfield S, Wraith J, Lynch TP (2007) Spatial and temporal variation in reef fish assemblages of marine parks in New South Wales, Australiabaited video observations. Mar Ecol Prog Ser 350:277-290

> Murray RW (1962) The response of the Ampullae of Lorenzini of elasmobranches to electrical stimulation. J Exp Biol 39: $119-128$

von der Emde G (1998) Electroreception. In: Evans DH (ed) The physiology of fishes. CRC Press, Boca Raton, FL, p 313-343

Willis TJ, Babcock RC (2000) A baited underwater video system for the determination of relative density of carnivorous reef fish. Mar Freshw Res 51:755-763

Wraith J (2007) Assessing reef fish assemblages in temperate marine park using baited remote underwater video. Masters thesis, University of Wollongong

Submitted: October 28, 2009; Accepted: March 17, 2010

Proofs received from author(s): May 21, 2010 